\title{
Are pioneering coyotes, foxes and jackals alien species? Canid colonists in the changing conservation landscape of the Anthropocene
}

\author{
Han Somsen and Arie Troumborst
}

\begin{abstract}
The pervasive influence of human agency on biodiversity in the Anthropocene gives rise to several new challenges for national and international wildlife law, including questions regarding what is natural and what is alien. Ultimately, a new vision and new rules are called for but in the meantime wildlife lawyers and other conservation professionals must work with conventional legal frameworks. Striking instances where vexing issues arise are the recent range expansions of certain canids. Coyotes Canis latrans and crab-eating foxes Cerdocyon thous in the Americas and golden jackals Canis aureus in Europe are progressively colonizing areas and countries where they did not previously occur. A key question is whether to consider this as acceptable extensions of natural range or whether the pioneering carnivores should be viewed as alien species, potentially triggering legal obligations of prevention, control and eradication. In addressing this question we draw on guidance provided under the Convention on Biological Diversity and other international legal frameworks, in which governments are forced to grapple with the application of long-standing concepts to new phenomena in an era of profound global change. Our analysis suggests that coyotes in Costa Rica, crab-eating foxes in Panama, and golden jackals in the Netherlands are not to be considered alien species, whether invasive or not. Thus, even if action to address adverse impacts by these canids on native biodiversity may sometimes be desirable, these species are not subject to legal requirements to combat invasive alien species.
\end{abstract}

Keywords Anthropocene, carnivores, coyote, crab-eating fox, golden jackal, international law, invasive alien species, range expansion

$\mathrm{T}$ he coyote Canis latrans dramatically expanded its range during the 2oth century, reaching all regions of North America and far into Central America (Flores, 2016; Hody \& Kays, 2018). Having followed the Pan-American Highway

Arie Troumborst (Corresponding author) and Han Somsen Department of European and International Public Law, Tilburg University, Montesquieu Building, Professor Cobbenhagenlaan 221, 5000 LE Tilburg, The Netherlands. E-mail a.trouwborst@tilburguniversity.edu

Received 22 June 2018. Revision requested 26 July 2018.

Accepted 12 September 2018. First published online 11 April 2019. and its adjacent cattle farms, and crossed the Panama Canal in 2010, this adaptable species is now on the margins of South America (Méndez-Carvajal \& Moreno, 2014; Hody $\&$ Kays, 2018). In Panama the coyote now coincides with the crab-eating fox Cerdocyon thous, a South American species undergoing a northward range expansion, producing a historical continental carnivore swap (Hody, 2016). In Europe, the golden jackal Canis aureus is displaying a similarly unprecedented range expansion (Arnold et al., 2012; Rutkowski et al., 2015; Trouwborst et al., 2015). The case of these three canids, which are progressively colonizing regions and countries where they probably did not historically occur, is different from the recent expansions of wolf Canis lupus range in North America and Europe, as the latter represent recolonizations. Moreover, the suspected drivers of the range expansions of the three smaller canids are anthropogenic, with the species benefiting from deforestation and other land-use changes, and the decimation of larger predators such as the wolf (Arnold et al., 2012; Flores, 2016; Hody \& Kays, 2018). The expansion of the range of these canids contrasts with the growing number of species that are negatively impacted by human activities.

With respect to the coyote's advance R. Kays asked: 'Is this something we should view as a natural expansion, that's a good thing, or that we should view as an invasive species, that's a bad thing?' He also noted 'In some ways that's a philosophical question, because in the end, there's nothing we can do about it' (Klein, 2018). To a significant degree, however, this is a legal question. Yet, as the Anthropocene proceeds and the global biodiversity crisis unfolds, the discipline of wildlife law is becoming more like refugee law, with conceptual footholds harder to find. Here we examine the question raised above by considering currently applicable law, using the standard legal research methods currently available. In addition, we note that this type of question is likely to increasingly challenge conventional legal frameworks.

The central insight regarding the Anthropocene is that human agency has infused and colonized nature. Through human agency, as Serres (1995, p. 86) put it, 'the Earth is moved' to a place where it was never destined to be and from which there is no returning. In this sense, coyotes, golden jackals and crab-eating foxes have been moved to new places, and other species to the brink of extinction, or across it. We can review these phenomena against the standards of current wildlife law, but must also accept that 
conventional legal texts are becoming increasingly unfit to inform a meaningful assessment.

In this respect, reliance on whatever is deemed to be natural as a measure to decide a species' fate in any given habitat is progressively becoming inappropriate. In the Anthropocene the natural is being substituted by human agency, and we therefore have a responsibility to exercise discretion in deciding where, and possibly if, a given species shall persist or disappear. Thus, a new vision and new rules are needed that transcend the nature/human dichotomy.

In the meantime it befalls upon legal scholars and courts, through traditional interpretative methods, to reconnect the normative realm implicit in existing wildlife law with an empirical reality that is becoming disengaged from it. The 1992 Convention on Biological Diversity (CBD; ratified by nearly all states except the USA) requires its 196 parties to '[p]revent the introduction of, control or eradicate those alien species which threaten ecosystems, habitats or species' (Article 8(h)). Similar requirements feature in other international legal instruments, such as:

- 1979 Convention on the Conservation of Migratory Species of Wild Animals (CMS), Articles III(4)(c) and $\mathrm{V}(5)(\mathrm{e})$;

- 2003 (revised) African Convention on the Conservation of Nature and Natural Resources, Article IX(2)(h);

- 1992 Convention for the Conservation of the Biodiversity and the Protection of Wilderness Areas in Central America, Article 24;

- 1979 Convention on the Conservation of European Wildlife and Natural Habitats (Bern Convention), Article 11(2)(b);

- 1992 EU Directive 92/43/EEC on the Conservation of Natural Habitats and of Wild Fauna and Flora, Article 22(b);

- 2014 EU Regulation 1143/2014 on the Prevention and Management of the Introduction and Spread of Invasive Alien Species (IAS Regulation).

Many national laws likewise aim to prevent introductions of invasive alien species and, when this fails, to control or eradicate them when feasible.

The question by R. Kays signals uncertainty regarding whether the coyote qualifies as an alien species in places such as Panama and Cape Breton Island. Confusion is apparent even within the IUCN Red List. The coyote assessment (Kays, 2018) considers the species native in all 10 countries where it occurs: the USA, Canada, Mexico, Guatemala, Belize, El Salvador, Honduras, Nicaragua, Costa Rica and Panama. However, the assessment of Dice's cottontail Sylvilagus dicei asserts that the coyote is a non-native carnivore in Costa Rica, where it poses a threat to the endemic rabbit, while simultaneously conceding that the coyote arrived in Costa Rica through a 'natural range expansion south following cattle' (Mora et al., 2016, p. 3).
Useful guidance is forthcoming from the CBD Conference of the Parties, which has defined an 'alien species' as a species 'introduced outside its natural past or present distribution' (CBD COP Decision VI/23, 2002, Annex). Introduction is understood as the 'movement by human agency, indirect or direct,' of a species 'outside of its natural range (past or present)'. The element of introduction by human agency also features in the definition of alien species employed in the EU's Invasive Alien Species Regulation: 'any live specimen of a species, subspecies or lower taxon of animals ... introduced outside its natural range' (Article $3(1)$ ). Under both instruments, an alien species is considered invasive when it threatens native biodiversity.

A canine example of such an invasive alien species is the red fox Vulpes vulpes in Australia, where it was introduced in the mid 1800 s for sport hunting, to the detriment of many native species (Global Invasive Species Database, 2018). A European example of an invasive alien canid is the raccoon dog Nyctereutes procyonoides, introduced into the western part of the former Soviet Union in 1920-1950 and spreading across Europe since (Kauhala \& Saeki, 2016). The latter example also illustrates how species, once introduced by human agency, continue to carry their alien species status when subsequently expanding by their own agency into neighbouring countries.

In contrast, canids colonizing areas beyond their former ranges entirely on their own would not seem to qualify as alien species, and therefore neither as invasive alien species, regardless of their impact on local biodiversity. Put another way, the mere fact that a species cannot be shown to have historically occurred in a place does not make it an alien species there (see also Trouwborst et al., 2015).

Yet, how liberally should the concept of 'movement by human agency, indirect or direct', from the CBD definition, be interpreted? Clearly, it encompasses organisms intentionally or accidentally trucked, shipped, flown or otherwise physically transported by people. But can the definition also encompass cases in which a range extension is somehow provoked or facilitated by humans?

The tentative answer would seem to be no. For instance, the EU's Invasive Alien Species Regulation 'applies to all invasive alien species' and therefore does not apply to 'species changing their natural range without human intervention, in response to changing ecological conditions and climate change' (Article 2(1)-(2)). Another pointer is a Recommendation by the Bern Convention's parties concerning range shifts driven by human-induced climate change. Concerned that 'native species moving to neighbouring areas may be considered as alien due to the fact that climate change is the result of human action and that such species may be unnecessarily controlled', the parties expressly interpreted the term alien species as 'not including native species naturally extending their range in response to climate change' (Recommendation No. 142, 2009, par. 1). Parties to 
the CMS have also adopted treaty interpretations welcoming rather than deterring species driven upwards or polewards by climate change (e.g. CMS COP Resolution 12.21, 2017).

In summary, current international wildlife law clearly suggests that the coyote in Costa Rica, crab-eating fox in Panama, and golden jackal in the Netherlands are not to be considered as alien species, whether invasive or not. Thus, they are also not subject to any legal requirements to combat invasive alien species.

It may be that measures to prevent damage inflicted by canids on native species in newly colonized territories (e.g. coyotes eating Dice's cottontails) are appropriate in certain situations, and this could conceivably include lethal control. Again, an evident role is reserved in this regard for international or national wildlife law, under which colonizing canids may be designated as, for example, protected, game or pest species. However, to regard the pioneering coyote, golden jackal and crab-eating fox as alien species to be discouraged or eradicated would be at odds with current international wildlife law.

Although our analysis is limited to clarifying the legal status of colonizing versus introduced species, we draw attention to the existence of various related issues. For instance, further complications arise where range expansions into non-historical areas result from a mixture of natural expansion and anthropogenic introductions. An illustration is the red fox in lowland areas of North America, where the species' establishment largely seems to have been a natural expansion, but was also influenced by introductions of foxes from Europe (Statham et al., 2012). Likewise, coyotes and golden jackals can hybridize with wolves and domestic dogs, raising vexing questions regarding the legal status of hybrid offspring (Trouwborst, 2014). These issues, along with de-extinction (Somsen, 2016) and assisted colonization (Trouwborst, 2015), are novel conundrums that wildlife law must come to grips with in the Anthropocene.

Acknowledgements AT was supported by the Netherlands Organization for Scientific Research, as part of the project Ius Carnivoris (No. 452-13-014). Helpful comments by two anonymous reviewers are gratefully acknowledged.

Author contributions Study design, legal analysis and writing the article: HS and AT.

\section{Conflicts of interest None.}

Ethical standards This research complied with the Oryx Code of Conduct.

\section{References}

Arnold, J., Humer, A., Heltai, M., Murariu, D., Spassov, N. \& HACKLÄNDER, K. (2012) Current status and distribution of golden jackals Canis aureus in Europe. Mammal Review, 42, 1-11.

Flores, D. (2016) Coyote America: A Natural and Supernatural History. Basic Books, New York, USA.

Global Invasive Species Database (2018) Species profile: Vulpes vulpes. Http://www.iucngisd.org/gisd/species.php?sc=66 [accessed 30 November 2018].

Hody, J.W. (2016) Canid collision. MSc thesis. North Carolina State University, Raleigh, USA.

Hody, J.W. \& KAYs, R. (2018) Mapping the expansion of coyotes (Canis latrans) across North and Central America. ZooKeys, 759, 81-97.

KaUHALA, K. \& SAEKI, M. (2016) Nyctereutes procyonoides. In The IUCN Red List of Threatened Species 2016: e.T14925A85658776. Https://www.iucnredlist.org/species/14925/85658776 [accessed 30 November 2018].

KAYs, R. (2018) Canis latrans. In The IUCN Red List of Threatened Species 2018: e.T3745A103893556. Https://www.iucnredlist.org/ species/3745/103893556 [accessed 30 November 2018].

KLEIN, J. (2018) Coyotes conquered North America. Now they're heading south. The New York Times, 24 May 2018. Http://www. nytimes.com/2018/05/24/science/coyotes-americas-spread.html [accessed 30 November 2018].

Méndez-Carvajal, P. \& Moreno, R. (2014) Mammalia, Carnivora, Canidae, Canis latrans (Say, 1823): actual distribution in Panama. Check List (Luis Felipe Toledo), 10, 376-379.

Mora, J.M., Ruedas, L. \& Smith, A.T. (2016) Sylvilagus dicei. In The IUCN Red List of Threatened Species 2016: e.T21209A45180947. Https://www.iucnredlist.org/species/21209/45180947 [accessed 30 November 2018].

Rutkowski, R., Krofel, M., Giannatos, G., Ćirović, D., Männil, P., Volokh, A.M. et al. (2015) A European concern? Genetic structure and expansion of golden jackals (Canis aureus) in Europe and the Caucasus. PLOS ONE, 10, e0141236.

Serres, M. (1995) The Natural Contract. The University of Michigan Press, Ann Arbor, Michigan, USA.

Somsen, H. (2016) Towards a law of the mammoth? European Journal of Risk Regulation, 7, 109-119.

Statham, M.J., Sacks, B.N., Aubry, K.B., Perrine, J.D. \& Wisely, S. M. (2012) The origin of recently established red fox populations in the United States: translocations or natural range expansions? Journal of Mammalogy, 93, 52-65.

Trouw воRst, A. (2014) Exploring the legal status of wolf-dog hybrids and other dubious animals. Review of European, Comparative \& International Environmental Law, 23, 111-124.

Trouwborst, A. (2015) The Habitats Directive and climate change. In The Habitats Directive in its EU Environmental Law Context (eds C. Born, A. Cliquet, H. Schoukens, D. Misonne \& G. Van Hoorick), pp. 303-324. Routledge, London, UK.

Troumborst, A., Krofel, M. \& Linnell, J.D.C. (2015) Legal implications of range expansions in a terrestrial carnivore: the case of the golden jackal (Canis aureus) in Europe. Biodiversity and Conservation, 24, 2593-2610. 